* Especialista em Direito Empresarial com ênfase em Direito do Trabalho e Direito Tributário pelo Instituto Paranaense de Ensino/Faculdades Maringá. Bacharel em Direito pelo UNICESUMAR. E-mail: annelise.es@gmail.com

** Doutor em Direito das Relações Sociais - Direito Processual Civil - pela (PUC/SP). Mestre em Direito Negocial, com concentração em Direito Processual Civil, pela Universidade Estadual de Londrina UEL. Especialista em Direito Civil e Processual Civil pelo Instituto Paranaense de Ensino. E-mail: rodrigo@rodrigo valente.com.br

\section{Anotação de responsabilidade técnica: a possibilidade de restituição e o entendimento dos tribunais}

\author{
TECHNICAL RESPONSIBILITY NOTE: THE \\ FINANCIAL RESTITUTION POSSIBILITY AND FEDERAL \\ COURT CASES \\ Annelise Cristine Emidio Sander * \\ Rodrigo Valente Giublin Teixeira **
}

Resumo: Discute-se a persistente ilegalidade da Taxa de Anotação de Responsabilidade Técnica exigida aos agrônomos e engenheiros civis pelos Conselhos Regionais - CREA's e pelo CONFEA, mesmo após a vigência da Lei 12.514/2011, que estabeleceu em seu art. 11 o limite quantitativo deste tributo.

Palavras-Chave: Regra Matriz de Incidência Tributária. Inconstitucionalidade. Estrita Legalidade Tributária. Critério Quantitativo. Obrigação Compulsória.

Abstract: Discusses the continuing illegality of Technical Responsibility Rate, required of Brazilians agronomists and engineers by the Regional Councils - like CREA's and CONFEA, even after the enactment of Law 12.514/2011, which established, in its article eleven, a quantitative limit for this tribute.

Keywords: Matrix Rule of Tax Incidence. Unconstitutionality. Tax Legality. Quantitative Criterion. Compulsory Obligation. 


\section{ANOTAÇÃO DE RESPONSABILIDADE TÉCNICA: DEFINIÇÃ̃O E FINALIDADE}

Anotação de Responsabilidade Técnica ou simplesmente $A R T$ é uma exigência do Conselho Federal de Engenharia e Agronomia, o CONFEA (Lei np 5.194/1966) ${ }^{1}$, e por consequência dos Conselhos Regionais de Engenharia e Agronomia-CREA's, tratando-se, pois, de documento formal do qual os profissionais devidamente habilitados em um dos Conselhos Regionais da classe registra as atividades técnicas exercidas e solicitadas em contrato.

Assim a $A R T$, atualmente, instituída e regulada pela Lei np 6.496 de 7 de dezembro de 1977, identifica os responsáveis técnicos pela execução de obras ou prestação de quaisquer serviços de engenharia e agronomia, celebrados por meio de contrato escrito ou verbal.

Para os engenheiros e agrônomos a $A R T$ representa verdadeiro acervo técnico das obras e serviços realizados. Enquanto, para os clientes, representa segurança jurídica de identificação e imputação de responsabilidade, que de certa forma, acaba por assegurar a qualidade da prestação dos serviços.

A exigência da $A R T$ pelo CONFEA e os CREA's é perfeitamente legal, por ter sido devidamente instituída em lei, qual seja, a Lei n ${ }^{\circ} 6.496$ de $1977^{2}$. Ocorre que a exigência da taxa de $A R T$ não apresenta a mesma legalidade. Apesar de ser determinada em lei, seus critérios de aferição são indicados por Resolução do CONFEA, caracterizando clara ilegalidade, a

\footnotetext{
${ }^{1}$ Com a publicação da Lei np 12.378 , de 31 de Dezembro de 2010, o CONFEA e por consequência os CREA's deixaram de representar a classe dos arquitetos, que devido esta nova lei, hoje, detém um conselho específico, o CAU/BR - Conselho de Arquitetura e Urbanismo do Brasil e os CAU's regionais, que regulamenta o exercício da Arquitetura e Urbanismo no Brasil.

${ }^{2}$ Lei 6.496 de 1977 - Institui a "Anotação de Responsabilidade Técnica" na prestação de serviços de engenharia, de arquitetura* e agronomia:

Art $1^{\circ}$. Todo contrato, escrito ou verbal, para a execução de obras ou prestação de quaisquer serviços profissionais referentes à Engenharia, à Arquitetura e à Agronomia fica sujeito à "Anotação de Responsabilidade Técnica" (ART).

Art $2^{\circ}$. A ART define para os efeitos legais os responsáveis técnicos pelo empreendimento de engenharia, arquitetura e agronomia.

$\S 1^{\circ}$. A ART será efetuada pelo profissional ou pela empresa no Conselho Regional de Engenharia, Arquitetura e Agronomia (CREA), de acordo com Resolução própria do Conselho Federal de Engenharia, Arquitetura e Agronomia (CONFEA).

$\S 2^{\circ}$. O CONFEA fixará os critérios e os valores das taxas da ART ad referendum do Ministro do Trabalho.

Art $3^{\circ}$. A falta da ART sujeitará o profissional ou a empresa à multa prevista na alínea "a" do art. 73 da Lei $\mathrm{n}^{\circ}$ 5.194, de 24 de dezembro de 1966 e demais cominações legais.
} 
ser demonstrada a seguir. Todavia, antes, devemos retomar alguns conceitos tributários.

\section{O PRINCÍPIO DA ESTRITA LEGALIDADE TRIBUTÁRIA}

A Carta Magna estabelece logo no artigo 5, inciso II que “ninguém será obrigado a fazer ou deixar de fazer alguma coisa senão em virtude de lei". Em direito tributário este princípio, o princípio da estrita legalidade, é de extrema relevância por delimitar a exigência dos tributos, quaisquer que sejam, impostos, contribuições de melhoria, contribuições especiais, empréstimos compulsórios e taxas, mediante expressão legal, e somente nestes casos, por tratarem-se de prestações pecuniárias, ou seja, obrigatórias.

Neste sentido também dispõe o Código Tributário ao reafirmar o princípio da legalidade no seu art. $3^{\circ}$, ao prescrever que "tributo é toda prestação pecuniária compulsória [...] instituída em lei..." (ALEXANDRE, 2010, p.110).

Nas palavras de Ives Gandra Martins e outros estudiosos ${ }^{3}$, o princípio da estrita legalidade seria o mais relevante e importante de todo o sistema tributário nacional, lastreado na máxima $O$ fisco tudo pode dentro da lei e nada fora dela ${ }^{4}$. Todavia, para o artigo 150, I da Carta Magna a legalidade não se apresenta como um direito subjetivo do Fisco, e sim como como um dever que lhe é imposto, i.e., como uma limitação ao poder de tributar, afinal "sem prejuízo de outras garantias asseguradas ao contribuinte, é vedado à União, aos Estados, ao Distrito Federal e aos Municípios exigir ou aumentar tributo sem lei que o estabeleça" (MARTINS, 2005).

É exatamente o que o princípio da legalidade, estrita legalidade, ou reserva legal, atrelados ao princípio da legalidade em direito administrativo, consubstanciado no artigo $37 \mathrm{da} \mathrm{CF}$, significa, limitar o poder de tributar do Estado. Retomando a ideia inicial de legalidade do artigo $5^{\circ}$, inciso II de que ninguém é obrigado a fazer ou deixar de fazer algo, senão em virtude de lei. Logo, não há base jurídica para a instituição de obrigação imposta pelo Estado, como é pagar tributos, senão em virtude de lei.

\footnotetext{
${ }^{3}$ Rubens Gomes de Souza, Gilberto de Ulhôa Canto, Alcides Jorge Costa, Carlos da Rocha Guimarães, Aliomar Baleeiro, Amílcar de Araújo Falcão e outros, na década de 50 e 60.

${ }^{4}$ Neste contexto, ao olhar para o Fisco (Receita Federal do Brasil, Procuradorias Estaduais e Municipais e seus centros de arrecadação e fiscalização tributária), não podemos dissociar do princípio da legalidade presente no art. $37 \mathrm{CF}$.
}

REVISTA DO DIREITO PÚBLICO, Londrina, v.8, n.3, p.193-212, set./dez.2013 
Novamente, a Constituição Federal trata do princípio da legalidade tributária ou reserva legal no artigo 146, inciso III, alínea $a$, destacando-se a determinação de lei complementar para estabelecer normas gerais em direito tributário, como a definição de tributos, suas espécies, fatos geradores, base de cálculo e contribuintes, obrigação, lançamento, crédito, prescrição e decadência (ALEXANDRE, 2010, p.110).

\section{A ILEGALIDADE DA COBRANÇA DA TAXA DE ANOTAÇÃO DE RESPONSABILIDADE TÉCNICA: A POSSIBILIDADE DE RESTITUIÇÃO}

A ilegalidade da Anotação de Responsabilidade Técnica reside exatamente no fato de ser instituída por Resolução do CONFEA, ainda que lei ordinária (Lei np 5.194/1966) lhe atribua competência para estipular valores de taxas da $\mathrm{ART}^{5}$.

As taxas são tributos ${ }^{6}$ que derivam da atividade direta do Estado dirigida a determinado contribuinte, podendo ser resultante de uma prestação de serviço ou do poder de polícia do estado ${ }^{7}$. A taxa é fato do Estado ${ }^{8}$, e não fato do contribuinte. Neste caso, quem realiza atividade tributável é o próprio Estado. No caso, a taxa de ART, trata-se de taxa derivada do poder de polícia do estado.

As taxas de polícia ${ }^{9}$ são aquelas em que o Estado em sentido lato $^{10}$ exerce a atribuição de fiscalização, limitando direitos e liberdades dos indivíduos em detrimento do interesse coletivo. Exemplificando, " $a$ construção de um prédio ou a instalação de uma empresa”. "Cabe à

\footnotetext{
${ }^{5}$ Art. $2^{\circ} \S 2^{\circ}$ da Lei 5.194/1966. O CONFEA fixará os critérios e os valores das taxas da ART ad referendum do Ministro do Trabalho. (BRASIL, 1966).

${ }^{6}$ Art. $5^{\circ}$ CF. Os tributos são impostos, taxas e contribuições de melhoria. (BRASIL, 1990).

${ }^{7}$ Art. 78 CTN. Considera-se poder de polícia atividade da administração pública que, limitando ou disciplinando direito, interesse (sic) ou liberdade, regula a prática de ato ou abstenção de fato, em razão de interesse (sic) público concernente à segurança, à higiene, à ordem, aos costumes, à disciplina da produção e do mercado, ao exercício de atividades econômicas dependentes de concessão ou autorização do Poder Público, à tranquilidade (sic) pública ou ao respeito à propriedade e aos direitos individuais ou coletivos.

Parágrafo único. Considera-se regular o exercício do poder de polícia quando desempenhado pelo órgão competente nos limites da lei aplicável, com observância do processo legal e, tratando-se de atividade que a lei tenha como discricionária, sem abuso ou desvio de poder. (BRASIL, 1966).

${ }^{8}$ Terminologia utilizada por Luciano Amaro (2011, p. 53).

${ }^{9}$ Terminologia, também, utilizada por Luciano Amaro (2011, p. 54), para designar e diferenciar as taxas derivadas do poder de polícia, das taxas derivadas de serviço público.

${ }^{10}$ Compreendendo a administração pública direta e indireta.
} 
administração pública verificar as normas pertinentes e conceder autorização, licença ou alvará". Podendo o Estado lato senso cobrar taxas referentes a esta fiscalização, pela verificação do cumprimento das exigências legais (AMARO, 2011, p. 55).

E, uma vez tratando-se a taxa de ART de tributo, de pagamento compulsório todos os seus elementos ${ }^{11}$, devem estar expressos em lei, e não por resolução. Os elementos devem estar descritos em lei em sentido estrito, não podendo a legislação delegar essa função para outro veículo legislativo, pois esta atribuição é de certo ilegal e inválida.

Outrossim, a Carta Magna, como anteriormente visto, no artigo 146, inciso III dispõe que apenas Lei Complementar estabelece "normas gerais em legislação tributária, especialmente sobre definição de tributos [...] dos respectivos fatos geradores, base de cálculo e contribuintes". (BRASIL, 1990).

Assim, é absurdo pensar em respeito à legalidade tributária, quando a taxa de ART é regulada por resolução, haja vista lei ordinária ter-lhe atribuído tal competência, quando sequer compete à lei ordinária definir tributos, fato geradores, base de cálculo e sujeito passivo, este elementos que compões a regra matriz de incidência tributária, como explanado acima, devem ser delimitados por lei complementar (art. 146, III CF). Assim, a cobrança da forma como é realizada é por óbvio ilegal. E, exatamente por esta razão, face a ilegalidade da cobrança, que os valores podem ser restituídos se pleiteados em juízo.

O Estado não deve estabelecer qualquer cobrança compulsória, como é o caso dos tributos, especificamente das Taxas de Polícia, como é o caso da taxa de ART sem previa cominação legal extensiva, dispondo sobre todos os elementos, como fato gerador, base de cálculo, quem é o contribuinte. Caso, contrário a arbitrariedade e liberalidade do Estado é tamanha, aproveitando-se por óbvio da compulsoriedade do tributo, em que os indivíduos são obrigados a pagar, para instituí-los livremente, voltando-se assim aos tempos da Monarquia.

A legislação a respeito da taxa de anotação de responsabilidade técnica de fato é um exemplo da crise da lei no sistema jurídico brasileiro. A crise

\footnotetext{
${ }^{11}$ Entendendo aqui, por elementos do tributo, a regra matriz de incidência tributária de Paulo de Barros Carvalho, quais sejam: elemento material, elemento temporal, elemento espacial, elemento pessoal (ou subjetivo) e elemento quantitativo, ainda que outras definições sejam utilizadas para definir os elementos da regra matriz tributária, como aspectos e critérios. No contexto do texto preferiu-se elementos.
} 
da lei, neste sentido pode ser sinteticamente traduzida no excesso de legislações confusas e sem a devida técnica legislativa, sendo, como no caso da ART, atribuídas a leis vigentes, mas inconstitucionais, afrontando assim diretamente os o princípios da legalidade e segurança jurídica (LAITANO, 2013).

A lei e o judiciário são o último reduto a segurança dos cidadãos frente às liberalidades da administração pública, e, portanto devem ser observados, respeitados e cumpridos, sob pena de se por em risco a República e o Estado Democrático de Direito.

\subsection{A Natureza Jurídica Parafiscal}

A quem discuta e afirme, inclusive com algumas decisões judiciais neste sentido, de que a taxa de ART seria na verdade "taxa" parafiscal 12 . Independentemente da denominação que receba (taxa ou contribuição) o tributo parafiscal tem por finalidade garantir a atuação do Estado em temas de interesse público primário e secundário, como, por exemplo, a intervenção no domínio econômico para regular oferta de determinado produto, incentivando ou desestimulando seu consumo, ou ainda, regular atividades de categorias profissionais. Trata-se de tributo de visa garantir atuação social e propositiva do Estado, diferente daquela formação de orçamento de direito voltada primariamente a manutenção administrativa do próprio Estado. Dentre essas espécies tributárias a taxa de ART, seria, segundo um entendimento doutrinário, mais do que uma contribuição social de interesse das categorias profissionais ou econômicas.

De fato, os tributos parafiscais são caracterizados por beneficiarem e serem cobrados por terceiros distintos daqueles que o instituíram, ou seja, o beneficiário do tributo não é a União, nem os Estados, ou Municípios.

Afastando-se o termo contribuição e entendendo a parafiscalidade como qualidade própria do tributo, a doutrina indica que a natureza jurídica parafiscal pode estar presente tanto em impostos como taxas. Sob esta égide, as espécies tributárias ${ }^{13}$, impostos e taxas, poderiam ter ou não natureza jurídica parafiscal (ROCHA, 1999).

Logo, o entrave teórico neste sentido diz respeito à taxa de anotação de responsabilidade técnica tratar-se de taxa de poder de policia ou

${ }^{12}$ Nesse sentido: Tribunal Regional Federal da Segunda Região, Apelação Civil no 33320; E Tribunal Regional Federal da Primeira Região. Agravo de Instrumento $n^{\circ}$ 5018603-67.2012.404.0000.

${ }^{13}$ Espécies tributárias segundo a teoria quadripartite. 
contribuição social de interesse das categorias profissionais ou econômicas.

Na verdade, pelo explanado acima, entendemos que a ART seria sim, uma taxa de poder de polícia, de natureza parafiscal. Enquanto, a contribuição social de interesse das categorias profissionais ou econômicas, as contribuições corporativas, seria tão somente as anuidades cobradas pelos CREA's.

\section{O ENTENDIMENTO DOS TRIBUNAIS}

É o entendimento dos tribunais quanto à ilegalidade da cobrança da taxa de Anotação De Responsabilidade Técnica - ART, face o desrespeito ao princípio da estrita legalidade tributária e/ou tipicidade tributária, qual seja, apenas Lei pode instituir, criar, majorar, estabelecer base de cálculo etc. de tributos. E, por ter sido estabelecido a taxa de ART por meio de Resolução do CONFEA e não por lei, resta caracterizada a sua ilegalidade. Este é o entendimento jurisprudencial majoritário ${ }^{14}$.

Ocorre que, com a publicação e vigência da Lei 12.514 de 2011, o entrave jurídico ganhou novos elementos. Assim, vislumbrando o que pode ser o novo entendimento jurisprudencial, presente na decisão do $A G n^{\circ}$ 5018603-67.2012.404.0000, da Primeira Turma do Tribunal Regional Federal da $4^{\text {a }}$ Região - TRF4a ${ }^{\text {a }}$ cujo Relator foi Jorge Antônio Maurique (D.E. 06/ 11/2012), a analisará a seguir (Tópico 4.1.).

\subsection{A Lei 12.514 de 2011 e o Posicionamento do TRF4a Região}

A Lei 12.514 de 2011 deu nova redação ao artigo $4^{\circ}$ da Lei no 6.932, de 7 de julho de 1981, que dispõe sobre as atividades do médico-residente, e tratou das contribuições devidas aos conselhos profissionais em geral, em tese, legalizando as contribuições das entidades de classe, face ao até então desrespeito ao princípio da estrita legalidade tributária, levando ao novo entendimento jurisprudencial contemporâneo, quanto a legalidade da

\footnotetext{
${ }^{14}$ Nesse sentido, têm-se: Superior Tribunal de Justiça, Embargos de Declaração no Recurso Especial $n^{0}$ 1006321; E, Tribunal Regional Federal da Segunda Região, Apelação em Mandado de Segurança ${ }^{\circ}$ 13593; E, Tribunal Regional Federal da Primeira Região. Apelação Civil nº 200333000209128, entre outros.
} 
Taxa de Anotação de Responsabilidade Técnica do CREA, representado decisão do Tribunal Regional Federal - TRF da 4ª Região, ora comentada:

Trata-se de agravo de instrumento, com pedido de efeito suspensivo, interposto pelo Conselho Regional de Engenharia e Agronomia de Santa Catarina - CREA/SC contra decisão que deferiu o pedido de antecipação dos efeitos da tutela, nos seguintes termos: [...] São requisitos para a antecipação dos efeitos da tutela, nos termos do art. 273 do Código de Processo Civil: requerimento da parte, prova inequívoca das alegações de fato, verossimilhança da tese jurídica sustentada, possibilidade de dano irreparável ou de difícil reparação e possibilidade de reversão do provimento antecipado. A anotação de responsabilidade técnica ou anotação de função técnica é o registro no conselho de fiscalização competente do ato que atribui ao profissional responsabilidade técnica pelo exercício da profissão por pessoa jurídica; pelo exercício de atividade meio própria da profissão por pessoa jurídica cuja atividade-fim esteja desvinculada da profissão; ou por obra, produto ou simples prestação de serviço profissional, nos casos em que é exigida (PEREIRA, Ricardo Teixeira do Valle; GAMBA, Luísa Hickel; MAURIQUE, Jorge Antônio; PAMPLONA, Otávio Roberto. Conselhos de Fiscalização Profissional. Doutrina e Jurisprudência. RT, 2001). Os Conselhos de Fiscalização Profissional recebem contribuições das espécies corporativas, assim previstas no art. 149 da CRFB, além de poderem cobrar taxas pelo exercício do poder de polícia ou pela prestação efetiva ou potencial de serviços públicos específicos e divisíveis. Nesse enfoque, a ART consubstancia taxa de polícia, razão pela qual ostenta natureza tributária, portanto mostrase imperiosa a autorização em lei para a fixação ou majoração da sua alíquota, sob pena de ofensa ao princípio da legalidade tributária, nos termos do disposto do artigo $150, \S 1^{\circ}$, da Constituição Federal. Com efeito, recentemente, em minha passagem pela $2^{\mathrm{a}}$ Turma do Tribunal Regional Federal da $4^{\mathrm{a}}$ Região, tive a oportunidade de discorrer sobre o tema objeto deste feito, momento em que apresentei voto-vista nos autos $\mathrm{n}^{\mathrm{o}}$ Apelação/Reexame Necessário $\mathrm{N}^{\mathrm{o}}$ 5001195-22.2011.404.7203/SC, relatado pelo Desembargador Rômulo Pizzolatti, que transcrevo a seguir: Voto-Vista Trata-se de apelação e remessa oficial em face de sentença que, julgando parcialmente procedente a ação, reconheceu a inexigibilidade das taxas de Anotação de Responsabilidade Técnica (ART), relativas às competências entre $08 / 2006$ e $05 / 2011$, por afronta ao princípio da legalidade. $\mathrm{O}$ voto do Exmo. Relator deu provimento ao recurso para reformar a sentença e declarar a exigibilidade da cobrança, no que foi acompanhado pelo Exmo. Juiz Federal convocado, Luiz Carlos Cervi. Peço 
vênia para divergir. A taxa de Anotação de Responsabilidade Técnica foi instituída pela Lei ${ }^{\circ}$ 6.496, de 07 de dezembro de 1977, nos seguintes termos: Art $2^{\circ}$ - A ART define para os efeitos legais os responsáveis técnicos pelo empreendimento de engenharia, arquitetura e agronomia. $\S$ $1^{\circ}$ - AART será efetuada pelo profissional ou pela empresa no Conselho Regional de Engenharia, Arquitetura e Agronomia (CREA), de acordo com Resolução própria do Conselho Federal de Engenharia, Arquitetura e Agronomia (CONFEA). $\S 2^{\circ}$ - O CONFEA fixará os critérios e os valores das taxas da ART ad referendum do Ministro do Trabalho. Art $3^{\circ}$ - A falta da ART sujeitará o profissional ou a empresa à multa prevista na alínea ‘ a ' do art. 73 da Lei $\mathrm{n}^{\circ}$ 5.194, de 24 de dezembro de 1966, e demais cominações legais. Posteriormente, a Lei $\mathrm{n}^{\circ}$ 6.994, de 26 de maio de 1982, estabeleceu: Art $2^{\circ}$ - Cabe às entidades referidas no art. $1^{\circ}$ desta Lei a fixação dos valores das taxas correspondentes aos seus serviços relativos e atos indispensáveis ao exercício da profissão, restritas aos abaixo discriminados e observados os seguintes limites máximos: (omissis) Parágrafo único - $\mathrm{O}$ disposto neste artigo não se aplica às taxas referentes à Anotação de Responsabilidade Técnica - ART, criada pela lei $\mathrm{n}^{\mathrm{o}} 6.496$, de 7 de dezembro de 1977, as quais poderão ser fixadas observado o limite máximo de 5 MVR. Finalmente a Lei no 12.514 , de 28 de outubro de 2011 estatuiu: Art. 11. O valor da Taxa de Anotação de Responsabilidade Técnica - ART, prevista na Lei no 6.496, de 7 de dezembro de 1977, não poderá ultrapassar R \$150,00 (cento e cinquenta reais). Parágrafo único. $\mathrm{O}$ valor referido no caput será atualizado, anualmente, de acordo com a variação integral do Índice Nacional de Preços ao Consumidor - INPC, calculado pela Fundação Instituto Brasileiro de Geografia e Estatística IBGE, ou índice oficial que venha a substituí-lo. Ocorre que o $\S 2^{\circ}$ do art. $2^{\circ}$ da Lei $n^{\circ} 6.496 / 77$, que estabelece a sistemática de fixação dos valores da taxa de Anotação de Responsabilidade Técnica (fixação pelo CONFEA, ad referendum do Ministro do Trabalho, teve sua inconstitucionalidade declarada pela Corte Especial deste Tribunal, no Incidente de Arguição de Inconstitucionalidade suscitado na Apelação 2007.70.00.013915-1, cuja decisão foi assim ementada: Tributário. Incidente de argüição de Inconstitucionalidade. art $2^{\circ}, \S 2^{\circ}$, da Lei $n^{\circ} 6.496 / 77$. ACOLHIMENTO. 1. Considerando que a Constituição Federal exige como requisito de validade e exigibilidade do tributo a sua previsão em lei, a qual deve conter, expressamente, todos os elementos necessários à sua caracterização, não é cabível que um ou mais desses elementos sejam instituídos por norma de natureza infra-legal, mesmo que haja lei autorizando. 2 . Incidente de argüição de inconstitucionalidade do artigo $2^{\circ}$, $\S 2^{\circ}$, da lei $\mathrm{N}^{\circ} 6.496 / 77$ acolhido.(Relatora Desembargadora Federal Luciane Amaral Corrêa 
Munch, de 24/09/2009). O fato de a Lei $\mathrm{n}^{\circ} 12.514 / 2011$ haver estabelecido um teto máximo em nada altera a moldura normativa tida por inconstitucional pela Corte Especial, uma vez que já naquela oportunidade havia um teto máximo para seu valor, estabelecido pela Lei $\mathrm{n}^{\circ} 6.994 / 82$ que, no particular, não foi revogada pela Lei $n^{0} 9.649 / 98$. De qualquer forma, o exame da hipotética inconstitucionalidade do art. 11 da Lei ${ }^{\circ}$ Lei $\mathrm{n}^{\mathrm{o}} 12.514 / 2011$ é matéria estranha à lide, uma vez que as taxas cuja restituição é reclamada nesta ação são todas anteriores à sua vigência. Seja como for, o fato de haver um limite máximo, traçado pela Lei, para a fixação do valor da taxa não supre o requisito de validade e exigibilidade do tributo, ditado pela Constituição Federal, qual seja, 'sua previsão em lei, a qual deve conter, expressamente, todos os elementos necessários à sua caracterização', tal como restou decidido pela Corte Especial no precedente acima referido. O princípio da legalidade impede que o valor da taxa seja fixado por norma infralegal, ainda que situado abaixo de um determinado patamar estabelecido pela lei. Neste sentido, cabe citar excerto do voto da Exma. Desembargadora Federal Luciane Amaral Corrêa Münch proferido no julgamento da Corte Especial acima citado: A Lei ${ }^{\circ}$ 6.496/77, no artigo em comento, determinou que o CONFEA fixaria os critérios e os valores das taxas da Anotação de Responsabilidade Técnica de maneira que houve a contrariedade à Constituição Federal, uma vez que, tal dispositivo legal, não poderia ter delegado a competência para fixação dos elementos constituintes do tributo por meio de normas infraconstitucionais expedidas por aquele órgão. A Lei $n^{0} 6.994 / 82$, visando completar a determinação dos elementos definidores da obrigação tributária em tela, não estabeleceu a base de cálculo da taxa de expedição das AFT's, apenas explicitou limites em que o órgão afim deveria se balizar. Ao não discriminar a base de cálculo e delegando mais uma vez ao CONFEA tal atribuição verifica-se, também, contrariedade ao que dispõe o texto constitucional. Considerando que na discussão posta nos autos, defendeu o CREA/PR que os Conselhos de fiscalização profissional tem amparo legal para fixarem as anuidades e as taxas de seus serviços, pois o legislador assim previu no art. $2^{\circ}$ da Lei $n^{\circ} 11.000 / 04$. Em julgamento pela Corte Especial do e. Tribunal Regional Federal da $4^{\text {a }}$ Região, foi declarada a inconstitucionalidade do termo 'fixar', constante no caput do art. $2^{\circ}$ da Lei $\mathrm{n}^{\circ} 11.000 / 04$, e da integralidade do $\S 1^{\circ}$ do mesmo artigo, por violação ao art. 150, I da Constituição Federal de 1988. O art. $2^{\circ}$ da Lei 11.000/04, autorizando os conselhos a fixarem as respectivas anuidades, incorreu em evidente afronta à garantia da legalidade tributária, reincidindo no vício que já acometera de inconstitucionalidade o art. $58, \S 4^{\circ}$, da Lei 9.649/98, declarado inconstitucional pelo STF no julgamento da ADIn 
1717-6. A propósito, transcrevo a ementa do julgamento deste incidente de argüição de inconstitucionalidade. TRIBUTÁRIO. LEGALIDADE ESTRITA. ANUIDADES DOS CONSELHOS DE FISCALIZAÇÃO PROFISSIONAL. INCONSTITUCIONALIDADE DO TERMO 'FIXAR', CONSTANTE DO ART. $2^{\circ}$, CAPUT, DA LEI 11.000/04, E DA INTEGRALIDADE DO $\S 1^{\circ}$ DO MESMO ARTIGO. 1. As anuidades cobradas dos profissionais e sociedades pelos conselhos Fiscalizadores são contribuições de interesse das categorias profissionais, tributos de competência da União, encontrando amparo no art. 149 da CF/88. Sendo tributos, essas contribuições submetem-se às limitações ao poder de tributar, a começar pela legalidade estrita, tal como estabelecido pelo art. 150, I, da CF. 2. O art. $2^{\circ}$ da Lei 11.000/04, autorizando os conselho s a fixarem as respectivas anuidade $\mathrm{s}$, incorreu em evidente afronta à garantia da legalidade tributária, reincidindo no vício que já acometera de inconstitucionalidade o art. 58, $\S 4^{\circ}$, da Lei 9.649/98, declarado inconstitucional pelo STF no julgamento da ADIn 1717-6. 3. Declarada a inconstitucionalidade do termo 'fixar', constante do caput do art. $2^{\circ}$ da Lei $\mathrm{n}^{\circ} 11.000 / 04$, e da integralidade do $\S 1^{\circ}$ do mesmo artigo, por violação ao art. 150, I da Constituição Federal de 1988. (Incidente de Argüição de Inconstitucionalidade na AMS n ${ }^{\circ}$ 2006.72.00.001284-9/SC, TRF4, Corte Especial, Rel. Des. Fed. Dirceu de Almeida Soares. D.E. 12.04.2007). Evidente, pois, diante das considerações, a inconstitucionalidade do art. $2^{\circ}, \S 2^{\circ}$, da Lei $n^{\circ} 6.496 / 77$, por afronta ao art. 150 , I, da Constituição Federal. Ante o exposto, com a máxima vênia dos ilustres votos que me antecederam, voto por negar provimento à apelação e à remessa oficial, mantendo a decisão monocrática, na linha das decisões da Corte Especial deste Tribunal acima reproduzidas. É como voto. Juíza Federal CLÁUDIA MARIA DADICO Assim reconheço a verossimilhança da tese defendida pelo autor, ante a inconstitucionalidade do art. $2^{\circ}, \S 2^{\circ}$, da Lei $n^{\circ} 6.496 / 77$, bem como a possibilidade de prejuízo de difícil reparação, uma vez que o recolhimento da exação indevida certamente prejudica a atividade do autor. Ante o exposto, DEFIRO o pedido de antecipação dos efeitos da tutela para suspender a exigibilidade da taxa alusiva à Anotação de Responsabilidade Técnica - ART. Cite-se. Intimem-se. Joinville, 02 de outubro de 2012. Sustenta o agravante, em síntese, que a decisão agravada não atentou para o fato de que atualmente a cobrança da taxa se dá com base na Lei $\mathrm{n}^{\circ} 12.514$, de 2011. Esses os apertados contornos da lide. Decido. A parte agravada ingressou com ação ordinária postulando a repetição Taxa de Anotação de Responsabilidade Técnica (ART) recolhida, com fundamento legal no art. $2^{\circ}, \S 2^{\circ}$, da Lei $n^{\circ} 6.496$, de 1977, nos últimos cinco anos, bem como a suspensão da cobrança do tributo, 
providência esta que foi deferida em sede de antecipação dos efeitos da tutela pela decisão agravada. Ocorre que a Lei n ${ }^{0} 12.514$, de 2011, supriu o vício reconhecido na lei anterior, pela Corte Especial deste Tribunal, no julgamento da Arguição de Inconstitucionalidade na APELRE ${ }^{\circ}$ 2007.70.00.013915-1, tendo em vista a fixação, por lei ordinária, da alíquota máxima do tributo. Confira-se: Art. 11. O valor da Taxa de Anotação de Responsabilidade Técnica - ART, prevista na Lei no 6.496, de 7 de dezembro de 1977, não poderá ultrapassar R $\$ 150,00$ (cento e cinquenta reais). Parágrafo único. O valor referido no caput será atualizado, anualmente, de acordo com a variação integral do Índice Nacional de Preços ao Consumidor - INPC, calculado pela Fundação Instituto Brasileiro de Geografia e Estatística - IBGE, ou índice oficial que venha a substituí-lo. Assim, a cobrança da taxa já pode ser feita validamente com base na Lei $\mathrm{n}^{\circ}$ 12.514, publicada em 31-10-2011, desde 29-01-2012, observadas as limitações constitucionais ao poder de tributar previstas no art. 150, III, b e c, da Constituição Federal. Como o óbice de inconstitucionalidade reconhecido na decisão agravada não mais existe desde antes da data em que foi publicada (18-04-2012), impõe-se sua suspensão, viabilizando a cobrança da taxa por parte do conselho agravante. Saliento que caso idêntico ao presente já foi objeto de apreciação pela Segunda Turma deste Regional: "AGRAVO DE INSTRUMENTO. CONSELHO PROFISSIONAL. TAXA DE ANOTAÇÃO DE RESPONSABILIDADE TÉCNICA (ART). INCONSTITUCIONALIDADE DA LEI No 6.496, DE 1977. SUPERVENIÊNCIA DA LEI No 12.514 , DE 2011. A Lei n ${ }^{\circ} 12.514$, de 2011, supriu o vício de inconstitucionalidade, reconhecido por este Tribunal, da cobrança da Taxa de Anotação de Responsabilidade Técnica (ART) com base no art. $2^{\circ}, \S 2^{\circ}$, da Lei ${ }^{\circ} 6.496$, de 1977, pelo que descabe, na vigência da nova lei, deferir a antecipação dos efeitos da tutela para desobrigar a parte do pagamento do tributo. (TRF4, AG 5007471-13.2012.404.0000, SEGUNDA TURMA, RELATOR P/ ACÓRDÃO RÔMULO PIZZOLATTI, D.E. 18/07/2012) Ante o exposto, suspendo a decisão agravada, com fundamento no art. 558 do Código de Processo Civil. Comunique-se com urgência ao juiz da causa. Intimese a parte agravada para responder. (TRF4, AG 501860367.2012.404.0000, Primeira Turma, Relator Jorge Antonio Maurique, D.E. 06/11/2012). Grifos nosso.

Nota-se que a ementa do TRF4 ${ }^{\mathrm{a}}$ região acima, apresenta-se como verdadeira aula quanto à ilegalidade da taxa de anotação de responsabilidade 
técnica, baseada no desrespeito ao princípio da estrita legalidade tributária.

Destaca-se que se trata de decisão, em sede de agravo de instrumento que combate o deferimento da tutela antecipada em primeiro grau, a qual, restou suspensa pelo Tribunal, sem, no entanto, julgar o mérito da questão.

Pois bem, a Lei 12.514 publicada em 31 de outubro de $2011^{15}$ com 12 artigos, alterou a redação de dois artigos de Leis diferentes ${ }^{16}$, com o objetivo principal de tratar das bolsas auxílios dos médicos residentes. Entre as alterações positivas pela Lei 12.514/2011 (BRASIL, 2011) estabeleceu-se o valor da bolsa dos médicos-residentes no valor de $\mathrm{R} \$ 2.384,82$ (dois mil, trezentos e oitenta e quatro reais e oitenta e dois centavos), em regime especial de treinamento em serviço de 60 (sessenta) horas semanais, sendo considerados contribuintes individuais do Regime Geral da Previdência Social - RGPS, não sendo considerada vantagem ao doador (pessoa que recebeu a bolsa-auxílio de médico residente), e, portanto, isento de pagar sobre o valor da bolsa-auxílio imposto de renda.

Aproveitando-se da publicação desta lei, por meio do artigo 11, estabeleceu-se que a Taxa de Anotação de Responsabilidade "não poderá ultrapassar R\$150,00 (cento e cinquenta reais)".

Ora, para que haja de fato respeito ao princípio da estrita legalidade, todo e qualquer tributo deve ser instituído por lei, fundamentado no fato de se tratar de uma prestação compulsória do contribuinte, o tributo deve ser expressamente estabelecido em lei todos os seus elementos (regra matriz tributária), ou seja, não basta instituir tributo em lei, dando-lhe uma denominação, "Taxa de Anotação de Responsabilidade Técnica" e descrevendo o fato gerador, "todo contrato, escrito ou verbal, para a execução de obras ou prestação de quaisquer serviços profissionais referentes à Engenharia, à Arquitetura (sic) e à Agronomia ${ }^{17}$ ". Para criar um tributo é necessário muito mais, deve-se expressamente indicar quando vai pagar (elemento temporal), para quem vai pagar (elemento subjetivo: sujeito ativo), quem deve pagar (elemento subjetivo: sujeito passivo), quanto vai pagar (elemento quantitativo: base de cálculo e a alíquota), local de ocorrência do fato gerador do tributo (elemento espacial) de forma expressa.

\footnotetext{
${ }^{15}$ Por força de estipulação legal, na própria Lei 12.514/2011, consoante artigo 12, a lei em questão entrou em vigência na data de sua publicação, qual seja 31 de Outubro de 2011.

${ }^{16}$ Alterou-se a redação do art. $4^{\circ}$ da Lei $6.932 / 1981$, por força do artigo $1^{\circ}$, bem como, alterou-se a redação do art. 25 da Lei 9.250/1995, por força do artigo $2^{\circ}$.

17 Art. $1^{\circ}$ da Lei $n^{\circ} 6.496$ de 7 de dezembro de 1977 - Lei que criou a ART.
} 
Não se pode pressupor elementos da regra matriz tributária de um tributo, e, sim, a regra matriz tributária em sua completude deve ser estabelecida em lei, e de preferência no mesmo texto normativo (AMARO, 2010, p. 53).

No caso da ART criada pela Lei 6.496 de 1977 é estabelecida unicamente pela expressão em três artigos, o artigo primeiro, o segundo e o terceiro. Em que se verifica a omissão de diversos elementos para criação do tributo (regra matriz de incidência tributária), além das ilegalidades de deixar o elemento quantitativo (valor do tributo) ${ }^{18}$ e demais elementos de incidência do tributo a serem instituídos por meio de Resolução do CONFEA ${ }^{19}$ (Ilegalidade).

$\mathrm{Na}$ verdade o único elemento que poderia se considerar regularmente estabelecido em lei (6.496/1977) é o elemento material da regra matriz de incidência tributária da taxa de ART, que em tese definiria o fato gerador do tributo ${ }^{20}$.

Ademais, afastando a omissão de diversos elementos ou até mesmo todos os elementos da regra matriz de incidência tributária da taxa de anotação de responsabilidade técnica não estarem devidamente estabelecidos em lei, nos voltemos, por ora ao limite quantitativo de $\mathrm{R} \$ 150,00$ (cento e cinquenta reais) trazido pela lei 12.514/2011.

18 Art. $2^{\circ} \S 2^{\circ}$ da Lei $6.496 / 1977$.

19 Art. $2^{\circ} \S 1^{\circ}$ da Lei 6.496/1977: “ [...] de acordo com Resolução própria do Conselho Federal de Engenharia, Arquitetura e Agronomia (CONFEA)".

${ }^{20}$ A possibilidade de poder considerar o critério material como o único regulado em lei, deve ao fato da análise e interpretação forçada dos artigos $1^{\circ}$ e $2^{\circ} \S 2^{\circ}$ da Lei 6.496/1977, que assim rezam:

Art $1^{\circ}$ - Todo contrato, escrito ou verbal, para a execução de obras ou prestação de quaisquer serviços profissionais referentes à Engenharia, à Arquitetura(sic) e à Agronomia fica sujeito à "Anotação de Responsabilidade Técnica" (ART).

Art. $2^{\circ} \xi 2^{\circ}$ - O CONFEA fixará os critérios e os valores das taxas da ART ad referendum do Ministro do Trabalho. (BRASIL, 1977).

Observa-se que o art. $1^{\circ}$ estabelece expressamente a situação fática abstrata em que os engenheiros e agrônomos (excluindo-se atualmente os arquitetos, por possuírem conselho de classe distinto) ficam obrigados a realizar a anotação de responsabilidade técnica. E, tão, somente, a ideia que sobre esta seria cobrado tributo (taxa) infere-se da redação do Art. $2^{\circ} \S 2^{\circ}$. Apenas, isto. Logo, o único elemento da regra matriz tributária que poderia ser considerado regularmente estabelecido em lei é o elemento material. Ocorre que esta interpretação é totalmente forçada, tentando dar legalidade e interpretar a lei em favor do conselho de classe, pois, se respeitado o art. $5^{\circ}$ da $\mathrm{CF}$ e o principio da estrita legalidade, e a interpretação da lei tributária em favor do contribuinte, nem sequer o elemento material de criação do tributo, taxa de Anotação de Responsabilidade Técnica, é definido em lei, e, sim a exigência da anotação da responsabilidade técnica dos engenheiros e agrônomos para aferição de responsabilidade pela obra, serviço e/ou empreendimento. 
$\mathrm{O}$ artigo 12 da mesma lei preceitua a vigência imediata da lei. Ocorre que, neste tocante, cabe a discussão se este limite deveria respeito aos princípios tributários da anterioridade e da anterioridade nonagesimal.

Se entendermos que até então na história normativa a taxa de ART não era devidamente instituída, por faltar os elementos da regra matriz de incidência tributária, sendo, portanto, ilegal e inconstitucional, e com a publicação da lei 12.514/2011, artigo 11, passaria então a suprir a ilegalidade (ainda que defendamos isto como um equivoco), sendo a partir de então legal, neste momento, consideraríamos a taxa de ART como instituída, e portanto, deve respeito sim aos princípios da anterioridade de exercício e da anterioridade nonagesimal (art. $195 \S 6^{\circ}$, estendida a todos os tributos EC 42/2003). Neste caso, o dispositivo em voga entraria em vigência em 90 dias da sua publicação, em 26 de janeiro de 2012.

Vejamos o entendimento do TRF4 ${ }^{\text {a }}$ supra, pode indicar uma futura decisão de mérito em dois sentidos, haja a fundamentação já explanada no acórdão que decidiu pelo efeito suspensivo do agravo de instrumento, de que a taxa de ART era ilegal até a publicação da Lei 12.514/2011, e com a indicação do limite quantitativo, não é mais (o que nos parece um equivoco), ou ainda, que a ilegalidade persiste com a publicação em seu art. 11, pela falta clara dos elementos que compõem o tributo, qual seja, a regra matriz de incidência tributária.

\section{CONSIDERAÇÕES FINAIS}

A Anotação de Responsabilidade Técnica - ART instituída pela lei 6.496/1977, acabou por instituir também por via reflexa a Taxa de Anotação de Responsabilidade Técnica - ART.

Ocorre que esta instituição não estipulou em lei os elementos que compõe a regra matriz de incidência tributária, da taxa então criada. Tratando-se de clara omissão legislativa, contraria aos princípios da legalidade, da legalidade administrativa e da estrita legalidade, afinal o tributo por ser uma obrigação compulsória do contribuinte (art. $3^{\circ} \mathrm{CTN}$ ) deve obrigatoriamente ser estabelecido em lei. Acrescentado, pela ilegalidade de expressamente dispor que o valor da taxa seria estabelecido por resolução do CONFEA, contrariando completamente o princípio da legalidade (art. 
37, caput da CF) e da estrita legalidade tributária (arts. 146, III, a e 150, I $\mathrm{CF})$.

Com o advento da Lei 12.514/2011, que trata da bolsa auxílio dos médicos residentes, aproveitou-se para instituir em seu artigo 11 o limite quantitativo para a taxa de ART no valor de R\$ 150,00 (cento e cinquenta reais), com a finalidade de por fim a discussão da ilegalidade da taxa, haja vista o debate da sua ilegalidade girar predominantemente em torno do artigo $2^{\circ} \S 2^{\circ}$ da Lei 6.496/1977.

Todavia, o que deve restar claro é que a ilegalidade da taxa de anotação de responsabilidade técnica não diz respeito tão somente a elemento quantitativo (o valor cobrado), a ilegalidade é intrínseca, diz respeito a praticamente toda a regra matriz de incidência tributária que não é expressamente estabelecida em Lei (resolução do CONFEA e portaria do CREA não são Lei stricto sensu), indicando quem é o contribuinte (sujeito passivo), o sujeito ativo (ente arrecadador), se existe responsável tributário e quem é ele, quando deve pagar o tributo (elemento temporal), em que local (base territorial), a alíquota e base de cálculo (elemento quantitativo).

Com a vigência da Lei 12.514/2011, que em seu art. 11 estabeleceu o limite quantitativo do valor da alíquota da taxa de anotação de responsabilidade técnica, de $\mathrm{R} \$ 150,00$ (cento e cinquenta reais), a ilegalidade da taxa de ART continua, afinal "limite" de alíquota não é alíquota nem é indicação de base de cálculo, continuando a não definir o elemento quantitativo da regra matriz tributária deste tributo, bem como os outros elementos de incidência, continuando clara ainda a existência da ilegalidade da taxa, não expressa em Lei (arts. $5^{\circ}$, II; 37 caput; 150, I; 146, III, $a$ todos da $\mathrm{CF}$ e art. $3^{\circ}$ do CTN).

Sem fundamento legal, o tributo não se justifica e não se fundamenta, afinal por ser uma obrigação compulsória, este só existe perante a legalidade, ou seja, a expressão em lei, desde o início da República.

\section{REFERÊNCIAS}

ALEXANDRE, Ricardo. Direito Tributário Esquematizado. 4. ed. Rio de Janeiro: Forense, São Paulo: Método, 2010. 
AMARO, Luciano. Direito Tributário Brasileiro. 12. ed. São Paulo: Saraiva, 2010.

AMARO, Luciano. Direito Tributário Brasileiro. 17. ed. São Paulo: Saraiva, 2011.

BRASIL. Constituição (1988). Constituição da Republica Federativa do Brasil. Brasília, 1990.

BRASIL. Lei Complementar $\mathbf{n}^{\mathbf{0}}$ 118, de 9 de Fevereiro de 2005. Altera e acrescenta dispositivos à Lei no 5.172, de 25 de outubro de 1966 Código Tributário Nacional, e dispõe sobre a interpretação do inciso I do art. 168 da mesma Lei. Disponível em: <http://www.planalto.gov.br/ ccivil_03/leis/lcp/lcp118.htm>.Acesso em: 18 jul. 2013.

BRASIL. Lei $\mathbf{n}^{\mathbf{0}} \mathbf{1 2 . 3 7 8}$, de 31 de Dezembro de 2010. Regulamenta o exercício da Arquitetura e Urbanismo; cria o Conselho de Arquitetura e Urbanismo do Brasil - CAU/BR e os Conselhos de Arquitetura e Urbanismo dos Estados e do Distrito Federal - CAUs; e dá outras providências. Disponível em:<http:/www.planalto.gov.br/ccivil_03/ _ato2007-2010/2010/Lei/L12378.htm>. Acesso em: 18 jul. 2013.

BRASIL. Lei $\mathbf{n}^{\mathbf{0}} \mathbf{1 2 . 5 1 4}$, de 28 de Outubro de 2011.D á nova redação ao art. 4ํ da Lei no 6.932 , de 7 de julho de 1981, que dispõe sobre as atividades do médico-residente; e trata das contribuições devidas aos conselhos profissionais em geral. Disponível em: $<$ http:// www.planalto.gov.br/ccivil_03/_ato2011-2014/2011/lei/112514.htm>. Acesso em: 18 jul. 2013.

BRASIL. Lei no 5.194, de 24 de Dezembro de 1966. Regula o exercício das profissões de Engenheiro, Arquiteto e Engenheiro-Agrônomo, e dá outras providências. Disponível em: <http://www.planalto.gov.br/ ccivil_03/leis/L5194.htm>. Acesso em: 10 set. 2013. 
BRASIL. Lei n 6.496, de 7 de Dezembro de 1977. Institui a "Anotação de Responsabilidade Técnica" na prestação de serviços de engenharia, de arquitetura e agronomia; autoriza a criação, pelo Conselho Federal de Engenharia, Arquitetura e Agronomia - CONFEA, de uma Mútua de Assistência Profissional; e dá outras providências. Disponível em: $<$ http:// www.planalto.gov.br/ccivil_03/leis/16496.htm>. Acesso em: 10 set. 2013.

BRASIL. Lei $\mathrm{n}^{\mathbf{0}} \mathbf{5 . 1 7 2}$, de 25 de outubro de 1966. Dispõe sobre o Sistema Tributário Nacional e institui normas gerais de direito tributário aplicáveis à União, Estados e Municípios. Disponivel em: $<$ http:// www.planalto.gov.br/ccivil_03/leis/15172.htm>. Acesso em: 10 set. 2013.

BRASIL. Superior Tribunal de Justiça. Embargos de Declaração no Recurso Especial no 1006321. Conselho nacional de engenharia, arquitetura e agronomia. Anotação de responsabilidade técnica. Leis 6.496/1977 e 6.994. Recorrente: Conselho Federal de Engenharia, Arquitetura e Agronomia - CONFEA. Recorrido: Elevadores Atlas Schindler S/A e outros. Segunda Turma. Relator: Herman Benjamim. Data do Julgamento: 19 fev. 2009.

BRASIL. Superior Tribunal de Justiça. Recurso Especial no 1110578. Direito tributário, taxas municipais, taxa de ilimunição pública. Recorrente: Município de Baretos. Recorrido: Artur Francisco Mori Rodrigues Motta. Primeira Turma. Relator: Ministro Luiz Fux. Data do Julgamento: 12 maio 2010.

BRASIL. Tribunal Regional Federal da Primeira Região. Apelação Civil no 200333000209128. Tributário, Administrativo. Conselho Regional de Engenharia Arquitetura e Agronomia - CREA, ART, Majoração por Resolução, Impossibilidade, Reserva Legal, arts. 149 e 150, i, da Constituição Federal. Apelante: CIA de Cimentos do Brasil. Apelado: Conselho Regional de Engenharia, Arquitetura e Agronomia CREA/BA e Conselho Federal de Engenharia, Arquitetura e Agronomia CONFEA. Sétima Turma. Relator: Carlos Eduardo Castro Martins. Data do Julgamento: 17 dez. 2002. 
BRASIL. Tribunal Regional Federal da Segunda Região. Apelação Civil $n^{0}$ 127421, constitucional e tributário. Anotação de Responsabilidade Técnica (ART), Leis $n^{\circ}$ 6.496/77 e 6.994/82. Apelante: Conselho Regional de Engenharia, Arquitetura e Agrononima - CREA/RJ. Apelado: Sergio Drumond Goncalves e outros. Terceira Turma Especializada. Relator: Paulo Barata. Data do Julgamento: 25 set. 2007.

BRASIL. Tribunal Regional Federal da Segunda Região. Apelação Civil n' 333201, constitucional e tributário. Anotação de Responsabilidade Técnica (ART), Leis n ${ }^{\circ}$ 6.496/77 e 6.994/82. Agravante: Elevadores Alpha LTDA. Agravado: Conselho Regional de Engenharia, Arquitetura e Agronomia - CREA/RJ. Terceira Turma. Relator: Luiz Norton Baptista de Mattos. Data do Julgamento: 27 nov. 2007.

BRASIL. Tribunal Regional Federal da Segunda Região. Apelação em Mandado de Segurança $n^{0}$ 13593. Tributário - Taxa de Anotação de Responsabilidade Técnica (ART) - Cobrança Indevida fixada por Resolução do CREA - Inconstitucionalidade Formal da Taxa - Ofensa ao Princípio da Reserva Legal. Terceira Turma. Apelante: Conselho Regional de Engenharia, Arquitetura e Agronomia do Estado do Rio De Janeiro - CREA/RJ. Apelado: PROMAQUINAS IND/ COM/ LTDA. Relator: Wanderley de Andrade Monteiro. Data do Julgamento: 5 dez. 2001.

CARVALHO, Paulo de Barros. (Cord.). Justiça Tributária: I Congresso Internacional de Direito Tributário. São Paulo: Max Limonad, 1998.

CARVAlho, Paulo de Barros. Curso de Direito Tributário. 23. ed. São Paulo: Saraiva, 2011.

LAITANO, Tatiana Michele Marazzi. A proposta da legística: Antes de legislar, é preciso conhecer bem o problema. Conjur, São Paulo, 11 jan 2013. Disponível em: $<$ http://www.conjur.com.br/2013-jan-11/tatianamarazzi-antes-legislar-preciso-conhecer-bem-problema $>$. Acesso em: 30 maio 2013. 
MARTINS, Ives Gandra da Silva. O princípio da legalidade nos tributos. Jus Navigandi, Teresina, ano 10, n. 851, nov.2005. Disponível em: $<$ http:/ /jus.com.br/revista/texto/7549>. Acesso em: 29 nov. 2012.

ROCHA, Marcelo Hugo da. Contribuições parafiscais. Jus Navigandi, Teresina, ano 4, n. 37, dez. 1999. Disponível em:<http://jus.com.br/ revista/texto/1420>. Acesso em: $11 \mathrm{dez} .2012$.

Artigo recebido em: $31 / 10 / 2013$ Aprovado para publicação em: 05/12/2013

Como citar: SANDER, Annelise Cristine Emidio. TEIXEIRA, Rodrigo Valente Giublin. Anotação de responsabilidade técnica: A possibilidade de restituição e o entendimento dos tribunais. Revista do Direito Público, Londrina, v.8, n.3, p.193-212, set./dez. 2013. DOI: 10.5433/1980511X. 2013v8n3p193. 